\title{
Intra-urban nocturnal temperature differences: a multivariate approach
}

\author{
Ingegärd Eliasson* \\ Göteborg University, Department of Physical Geography, Laboratory of Climatology, Earth Sciences Centre, \\ S-41381 Göteborg, Sweden
}

\begin{abstract}
The possibility of predicting nocturnal intra-urban air temperature differences on the basis of meteorological data from climatic stations was analysed. Three years of recording at an urban canyon and a nearby open area in the city of Göteborg, Sweden, formed the basis of the analyses. The urban canyon - urban open area temperature differences $\left(\Delta T_{c_{-0}}\right)$ were best estimated when the data was first classified with reference to the amount of cloud cover and then fitted to a non-linear regression equation which included the wind speed at the urban open area $(10 \mathrm{~m}$ level). The study shows that the degree of intra-urban temperature variations can be predicted using a fairly sumple methodology. The methodology and the general pattern of the model could be helpful as a complementary tool in urban land use planning for cities with a structure similar to Göteborg.
\end{abstract}

KEY WORDS: City climate - Urban canyon - Air temperature S Street geometry Applied climatology Urban planning

\section{INTRODUCTION}

The greatest challenge for urban climatologists is to translate the findings of their scientific research into applicable models for urban planning. Many attempts have been made to model the effect of urban development on the local microclimate. Yet complete models for urban planning are not available at this time and there is still a striking gap between climate and design.

Numerical models are continuously being developed to simulate the relevant processes that shape the urban climate. As early as 1951, Sundborg related the heat island intensity of Uppsala, Sweden, to simple meteorological variables, i.e. cloudiness, wind speed, temperature and absolute humidity, by means of a multiple regression analysis. In 1969, Myrup used the energy budget approach to model the urban heat island and Terjung \& O'Rourke (1980a, b) made a computer simulation of the effect of canyon geometry on the development of a nocturnal heat island. Simula-

•E-mail: ingegard@gig.gu.se tions of the same type of effect were made by Arnfield (1990) and Todhunter (1990). An urban climate simulation was also used by Arnfield (1982) to predict the albedo and emissivity of a city. In order to simulate urban temperature patterns and wind patterns on both the meso- and microscale, Eichhorn et al. (1988) developed two complementary 3-dimensional nonhydrostatic models. Johnson et al. (1991) developed a model to simulate the cooling of rural and urban canyon surfaces on calm, cloudless nights, and Yoshida (1992) estimated the heat transfer in an urban canyon by means of a numerical simulation using a simple physical model.

Many of these models have been validated by comparision with field data. The validation of such models can be complex, as it requires measurements and input parameters which may be difficult to obtain (Voogt \& Oke 1991). Thus, in spite of the importance of these models, it is often very difficult to use them directly in the planning process. Instead, local climate maps (Lindqvist \& Mattsson 1989, Lindqvist 1991) together with guidelines for planning (e.g. Oke 1988, Evans \& Schiller 1991, Kuttler 1993) have been shown to be useful tools in urban planning. 
Urban geometry often is theorized to be one of the major factors leading to the development of urban heat islands. For example, the maximum heat island intensity has been proven to correlate well with the mean sky view factor (SVF) of the city centre for a number of cities around the world (Oke 1981, Park 1987). Despite the numerous heat island studies in the literature, there is less clarity regarding the effect of geometry on the temperature pattern within a single city. However, field observations (Bärring et al. 1985) and simulationbased studies (Todhunter 1990) have shown that the heterogeneous urban microclimate is attributable to the variable urban geometry within a given land-use category. For many reasons, not least those of urban planning, intra-urban temperature differences are of greater interest than temperature variations between cities. Previous papers have presented results from an investigation of urban climate and structure carried out in Göteborg. Sweden (Eliasson 1990/91, 1992, $1994,1996)$. The primary purpose of the survey was to study the effect of urban geometry on temperature within the city centre and surrounding urban areas. Great importance was attached to distinctions between the effect of geometry on surface and air temperatures. The role of geometry was evaluated for night periods, as the heat island is known to be most intense at this time. During clear and calm weather conditions, the relationship between surface temperature and street geometry in the city centre proved to be statistically significant (Eliasson 1992). However, in spite of large temperature gradients between urban districts with different land use, the corresponding relation for air temperature and street geometry was not statistically significant (Eliasson 1996). Nocturnal air temperature differences of up to $3^{\circ} \mathrm{C}$ were recorded on nights with light wind and clear skies between a dense canyon and a nearby open area within the city centre. Moreover, in all seasons, the mean urban canyon heat island intensity was increased and persisted for a longer time as compared with the heat island calculated from the urban open area station data (Eliasson 1994, 1996).

The aim of the present paper was to analyse whether and to what extent intra-urban temperature differences can be modeled using equations based on recordings of meteorological parameters at climatic stations. If an urban climate model is to be of practical use, the input data must be easily accessible from, for example, a standard meteorological station within the area. Thus the present analysis is based on data from a $3 \mathrm{yr}$ measuring period $(1988,1989,1990)$ of the canyon/ open area temperature difference $\left(\Delta T_{c-o}\right)$ recorded in Göteborg (Eliasson 1994, 1996). The analysis is restricted to nocturnal data (see above) and is divided into 2 separate parts. In the first part, the basic data is classified with respect to cloudiness and, in the second, data is analysed by multiple regression.

\section{MEASUREMENTS OF CLIMATIC PARAMETERS}

The measurements were carried out in the city of Göteborg $\left(57^{\circ} 42^{\prime} \mathrm{N}_{i}\right.$ Fig. 1), located on the west coast of Sweden and built up around the shores of the Göta River. The metropolitan Goteborg area, including the city centre and suburbs, has a population of approximately 700000 . Data from 3 rural standard meteorological stations are available (Stns 4, 5 and 6 in Fig 1.) The climate conditions at these stations can be very different, especially during anticyclonic weather conditions, as reported by Eliasson \& Holmer (1990). The meteorological station at Säve airport, located $9 \mathrm{~km} \mathrm{NW}$ of the city centre, was selected as the rural station for this study.

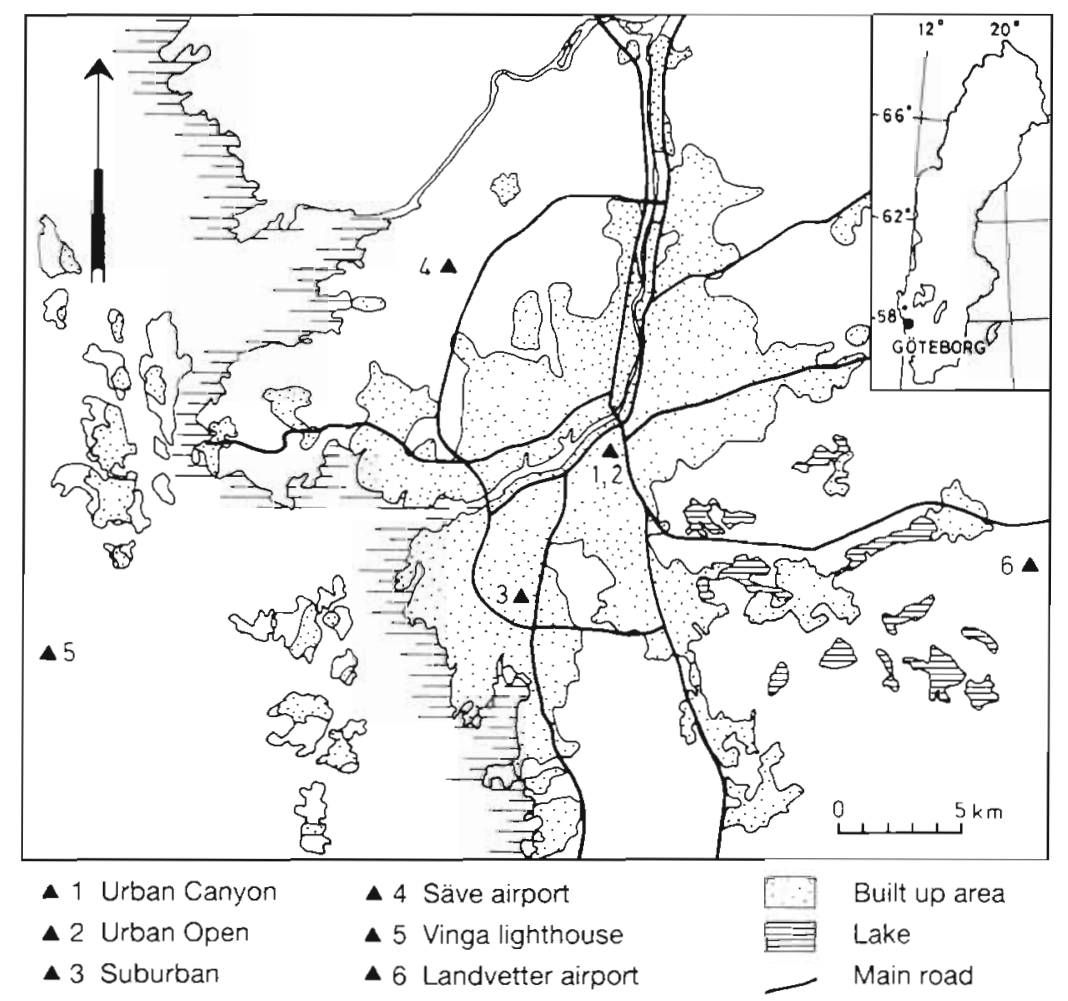

Fig. 1. Goteborg, Sweden, showing the location of the meteorological stations and the built-up area. [Data from Stn 3 was analysed by Eliasson (1994) but is not presented in this paper] 
The inner city of Göteborg has a classical European city structure. The city was founded in 1621 and the city core was planned by Dutch engineers, which gave the city a characteristic design. The oldest part of the city is located between the Göta River and a system of old canals. In this area, there is a mixture of old and new buildings, but the old, dense structure remains. The streets are, with some exceptions, oriented in an ENE-WSW and NNW-SSE direction. The building heights vary between 10 and $15 \mathrm{~m}$ and the average street width is $7 \mathrm{~m}$. The SVF of the canyons vary between 0.25 and 0.45 . South of the canals lies a part of the city, built around 1860, with a more heterogeneous geometry. Some streets in this area are quite wide, $45 \mathrm{~m}$, but others are narrower, about $13 \mathrm{~m}$. The heights of the buildings in this part of the city vary between 5 and $25 \mathrm{~m}$ but the average height interval is 17 to $22 \mathrm{~m}$. The SVF of the canyons vary between 0.5 and 0.9 and the streets are, with some exceptions, oriented in a N-S and E-W, or a NW-SE and NE-SW pattern. To the northeast is a large open area. Small parks are scattered within this southern part, which is bordered by a large park in the southwest.

Temperature, wind and humidity were recorded at 2 urban climatic stations, located south of the canals, during a 3 yr period. The urban climatic stations represent 2 different types of building geometry, as one is situated in a dense canyon with an SVF of 0.5 and the other in an open area (SVF close to 1.0$) 400 \mathrm{~m}$ away (Fig. 1, Stns 1 and 2).

The street canyon (Stn 1) is formed by symmetrical buildings $120 \mathrm{~m}$ long and $20 \mathrm{~m}$ high. The width of the street is $14 \mathrm{~m}$, giving a height/width ratio of 1.4 . The façades of the buildings in the canyon are of brick. Fig. 2 shows the location of instruments in the canyon. The air temperature was measured at 4 points. For

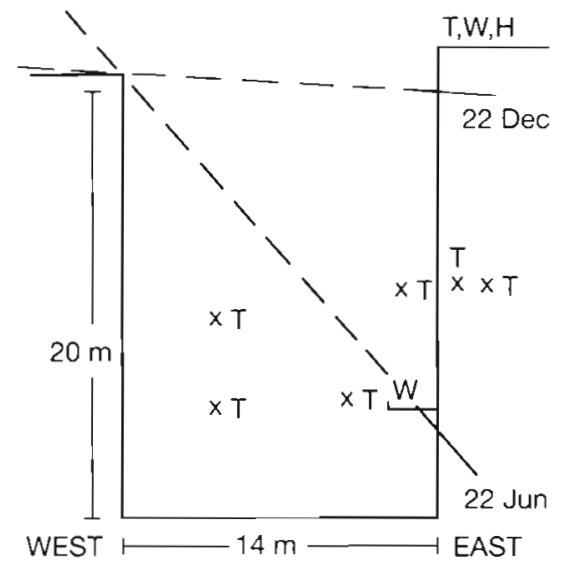

Fig. 2. Instrumentation at the street canyon and penetration of solar radiation into the canyon at 14:00 h during summer and winter. $T$ : temperate; $W$ : wind; $H$ : humidity practical reasons, these points were located between 4 and $10 \mathrm{~m}$ above the street surface. The wind speed and direction were monitored within the canyon at a point $4 \mathrm{~m}$ away from the east façade and $5 \mathrm{~m}$ above the street surface. The temperature was also measured at 2 points $(2$ and $5 \mathrm{~cm}$ ) inside the east wall. On the roof of the east building, temperature, wind and humidity were monitored at $2 \mathrm{~m}$ above the surface of the roof.

The penetration of solar radiation into the canyon at 14:00 $\mathrm{h}$, when the solar azimuth angle is perpendicular to the orientation of the canyon, is also marked in Fig. 2. On June 22, the solar altitude is $48^{\circ}$; thus, at this time, almost all of the east wall is sunlit. On December 22 , owing to the low solar altitude $\left(3^{\circ}\right)$, only the uppermost $2 \mathrm{~m}$ of the east wall is sunlit.

The open area (Stn 2 ) is covered mainly by gravel and is used for sports. The air temperature was measured at 2 and $10 \mathrm{~m}$ above the surface. Relative humidity was recorded at $2 \mathrm{~m}$ above the surface, and the wind (speed and direction) was monitored at 5 and $10 \mathrm{~m}$ above the surface.

The temperature was recorded at both stations using wire-wound resistance thermometers, Pt (100 ohm) and $\mathrm{Ni}(1000 \mathrm{ohm})$, protected by radiation shields. The relative humidity was measured by the capacity method and the wind speed and direction were recorded by Vaisala cup anemometers (VAA15) and a Vaisala wind vane (VAW15). All sensors were calibrated in a climatic chamber before and after the measuring period and in situ at regular intervals during the measurements. Hourly mean and $10 \mathrm{~min}$ mean values were stored in a computer at each station. To limit the influence of errors caused by the variations between the temperature probes, the data were corrected taking into account the calibration results. However, for interpretation of the air temperature difference between the 2 urban sites, only differences greater than $\pm 0.5^{\circ} \mathrm{C}$ were taken into consideration. The 2 urban stations were continuously run during the measuring period, although minor gaps do exist in the gathered data owing to technical difficulties.

The 3 stations, Säve airport, the urban canyon and the urban open area, used in the analysis presented in this paper are located in areas of similar topography and landscape morphology, i.e. relatively flat areas consisting of clay deposited during the last glacial period. Compared with the other 2 rural standard meteorological stations, Landvetter airport and Vinga lighthouse (Fig. 1), the area surrounding Säve airport, with respect to geomorphology and distance to the sea, corresponds best with the urban stations. Hourly data on wind, cloud cover, air temperature and air humidity were used from the station at Säve airport. 
The station (Stn 4, Fig. 1) is located $3 \mathrm{~km}$ east of the coastline, while the distance from the city centre to the sea is approximately $8 \mathrm{~km}$. Previous studies in Göteborg have shown that the urban-rural temperature difference between the station at Säve airport and the urban stations is to be regarded as a minimum value for the heat island, due to the proximity of the sea. Automobile traverses have shown larger temperature differences between the city centre and the eastern suburbs than between the centre and the western parts of the city. The nocturnal advective influence of the sea upon the heat island is small, however, due to the strong temperature gradient, directed towards the warmer sea, which often exists in the coastal area during clear and calm winter nights. This temperature difference induces a weak air flow, the land breeze, directed from the city centre to the sea (Eliasson \& Holmer 1990). Weak land breeze flows also often occur during clear and calm summer nights. Thus the nocturnal advective influence of the sea upon the urban heat island is limited during both winter and summer. This is in agreement with other studies which have shown that strong horizontal temperature gradients are preserved despite the smoothing effects of advection (Carlson et al. 1981).

\section{DATA ANALYSIS}

The air temperature difference between the canyon and the open area $\left(\Delta T_{c-0}\right)$ remained on average at a constant level throughout the night during the $3 \mathrm{yr}$ measuring period (Eliasson 1994). Each night hour was thus analysed separately, and no consideration was given to the time after sunset in the analysis of data. As earlier analyses of the data showed small variations within the canyon (Eliasson 1996), the canyon temperature value $\left(T_{c}\right)$ used in the present paper was a mean value of the 4 measurements between 4 and $10 \mathrm{~m}$ inside the canyon (Fig. 2). In order to obtain a comparable value, the open area temperature value $\left(T_{0}\right)$ used was a mean value of the measurements at 2 and $10 \mathrm{~m}$ at the open area. The data for the $3 \mathrm{yr}$ period was grouped into monthly sums, i.e. the data represented by January includes all nighttime hours during the month of January in 1988, 1989 and 1990. The analyses were divided into 2 parts.

Part 1: The data ware classified into 3 categories according to amount of cloud cover, i.e. clear $(\leq 2$ octas), semicloudy ( 3 to 5 octas) and cloudy ( $\geq 6$ octas). This follows the classification used by the Swedish Meteorologicai and Hydrological Institute (SMHI). For each cloudiness class and each night hour, $\Delta T_{\text {c-o }}$ was related to the wind speed at the different climatic stations.
Part 2: A multiple regression analysis was performed using the different meteorological variables recorded at the climatic stations. These variables were: total amount of cloud cover, distance from the surface to the lowest cloud base, air temperature, absolute air humidity, wind speed and wind direction; in addition, a seasonal factor was introduced.

\section{URBAN CANYON/OPEN AREA TEMPERATURE DIFFERENCES UNDER CLEAR, SEMICLOUDY AND CLOUDY CONDITIONS}

The relationship between $\Delta T_{c-0}$ and the wind speed at the rural and urban stations for clear, semicloudy and cloudy weather conditions was analysed. The results from this comparison are given for clear and cloudy conditions during the month of October in Fig. 3. In October 143 nighttime hours were classified as clear and 226 as cloudy. Not unexpectedly, the largest $\Delta T_{\mathrm{c}-\mathrm{o}}$ occurred at low wind speeds during clear conditions. Differences greater than $1^{\circ} \mathrm{C}$ (positive values of $\Delta T_{c-o}$ indicate a higher canyon temperature) occurred at wind speeds $\leq 2 \mathrm{~m} \mathrm{~s}^{-1}$ at the rural station (Fig. 3a) and wind speeds lower than $1 \mathrm{~m} \mathrm{~s}^{-1}$ at the urban open area station (Fig. 3c). The relationship has an exponential form and the best fit of the points was given by the non-linear equation $\Delta T_{c-0}=a+b \mathrm{e}^{-c U}$, where $a, b$ and $c$ are the regression coefficients and $U$ is the wind speed. The non-linear equation form was suggested by Sundborg (1951) for the prediction of urban-rural air temperature differences.

Wind speeds at Swedish standard meteorological stations are given only as integers (statistics from $\mathrm{SMHI}$ ), which increased the scatter of the points and resulted in lower correlation coefficient values $(R=0.73$, Fig. 3a) compared to the urban open area $(R=0.92$, Fig. 3c). The lower correlation coefficients found for the relationship between $\Delta T_{c-0}$ and the rural wind speed is an effect of both the integer variables and the distance between the urban and rural sites. A test showed that if the integer format (rounded values) was also used for the relationship between $\Delta T_{c-o}$ and the urban open area wind speed, the correlation coefficient decreased to 0.86, which is still higher than the correlation coefficient for the rural station (Fig. 3a). This indicates that the urban-rural distance effect is important. The correlation coefficients were lower during cloudy conditions, as can be seen in Fig. 3b, d, where the points are highly scattered.

The relationships between $\Delta T_{c-o}$ and the wind speed at other urban locations were also examined (but are not shown in the figures in this paper). The regression and correlation between $\Delta T_{c \cdot 0}$ and the wind speed at $5 \mathrm{~m}$ in the open area and at the canyon roof exhibited 
a) $\operatorname{RURAL}(\mathrm{c} \leq 2 / 8)$

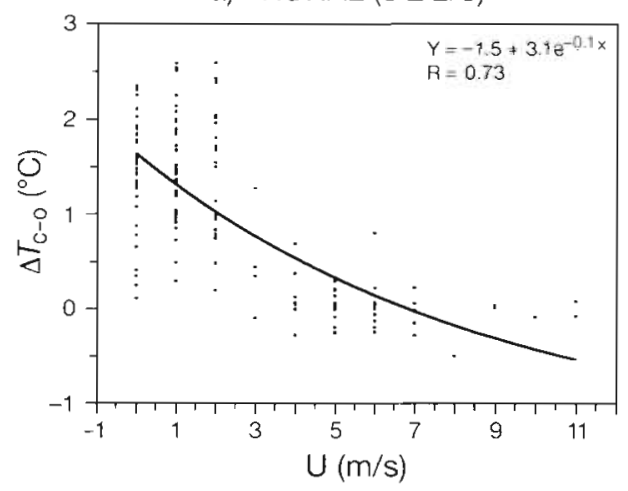

c) OPEN AREA (c $\leq 2 / 8)$

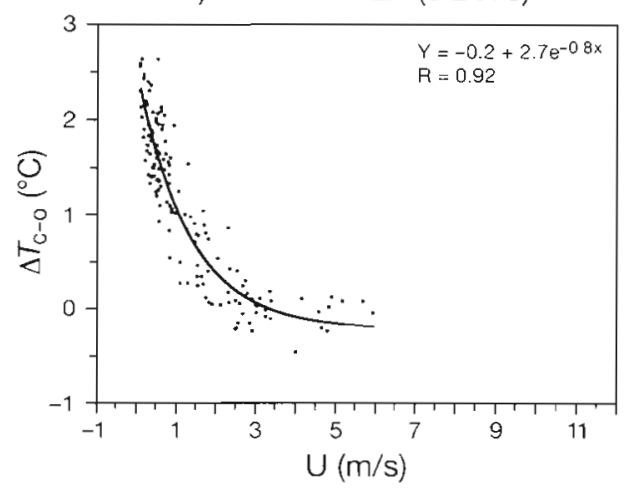

b) RURAL $(c \geq 6 / 8)$

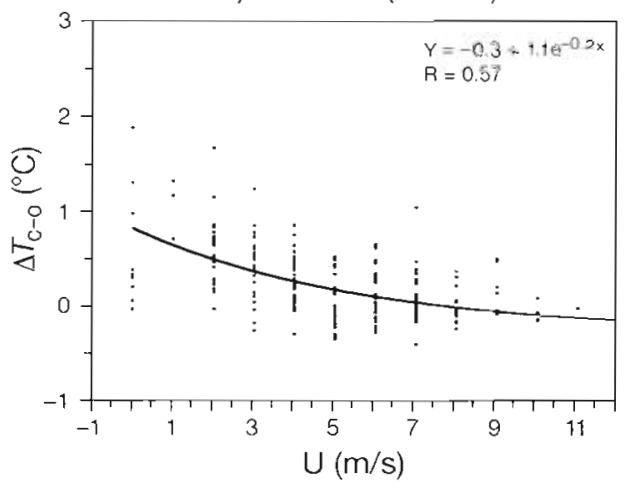

d) OPEN AREA (c $\geq 6 / 8)$

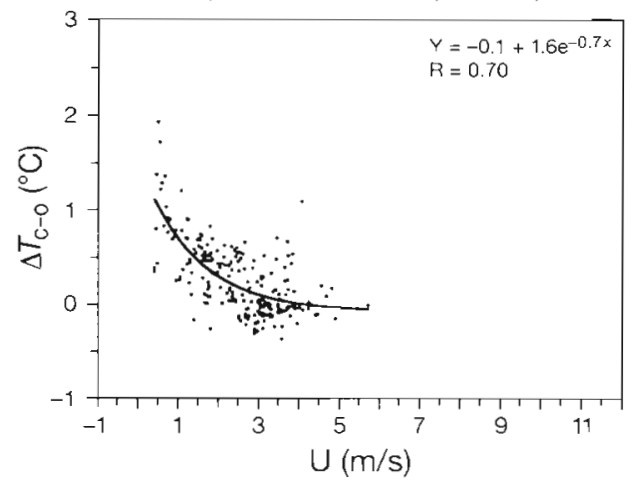

Fig. 3. Relationship between $\Delta T_{c-0}$ and wind speed (at $10 \mathrm{~m}$ ) during clear and cloudy conditions in October. Positive $\Delta T_{c-0}$ indicates higher canyon temperature. (a) Rural/clear, (b) rural/cloudy, (c) urban open area/clear, (d) urban open area/cloudy. Cloudiness (c) indicated in octas

The function estimated by the regression analysis

patterns very similar to those for the open area at $10 \mathrm{~m}$, with $\mathrm{R}=0.90$ and $\mathrm{R}=0.84$, respectively, for clear conditions. In the canyon the wind speed was reduced by the buildings and in general was less than $2 \mathrm{~m} \mathrm{~s}^{-1}$. The relationship between $\Delta T_{\mathrm{c}-\mathrm{o}}$ and the canyon wind was thus not very significant: the correlation coefficient for clear conditions was 0.66 , and for cloudy conditions 0.46

The basic pattern for the month of October, shown in Fig. 3 , is representative for all months, i.e. the best correlation was found between $\Delta T_{\mathrm{c}-\mathrm{o}}$ and the wind speed at $10 \mathrm{~m}$ in the urban open area. The urban open area station, representing an open area within a city, will therefore be further examined below. It would of course have been more advantageous to use a standard meteorological station. However, since the temperature differences were most pronounced at low wind speeds, the statistics available from SMHI were insufficient for the analysis due to their weaker correlation.

The relationship between $\Delta T_{c \cdot 0}$ and the wind speed at the open area $(10 \mathrm{~m}$ level) for clear conditions throughout the year is shown in Fig. 4. To minimise the number of diagrams, every fourth month is shown, representing each season. The 2 variables $\Delta T_{c-0}$ and wind speed $(U)$ are closely related for all months, as shown by the high correlation coefficients, but are highest in October $(R=0.92)$ and lowest in July $(0.76)$. shows that the wind speed $(U)$ at which $\Delta T \geq 1^{\circ} \mathrm{C}$ varies with the season; in January the threshold value is $0.5 \mathrm{~m}$ $\mathrm{s}^{-1}$ and in July $1.5 \mathrm{~m} \mathrm{~s}^{-1}$. April and October show threshold values of 1.25 and $1.0 \mathrm{~m} \mathrm{~s}^{-1}$ respectively. A possible explanation of these seasonal variations is the longer days and greater solar height during summer, which would result in a greater daytime heating of the canyon area. The short nights in July, approximately $6 \mathrm{~h}$, result in a preservation of the heat in the buildings and thus a greater $\Delta T_{\mathrm{c}-\mathrm{o}}$ which can be sustained longer and is less sensitive to advection compared to the winter situation.

The regression equations for clear conditions were generally similar over the year, although small variations occurred, such as a somewhat higher $\Delta T_{\mathrm{c}-\mathrm{o}}$ observed during the summer months. The $\Delta T_{\mathrm{c}-\mathrm{o}}$ /open area wind speed $(10 \mathrm{~m})$ relationship is shown for the total 3 yr period in Fig. 5. The regression equation is

$$
\Delta T_{\mathrm{c}-\mathrm{o}}=-0.2+2.4 \mathrm{e}^{-0.7 U}
$$

and the correlation coefficient $\mathrm{R}=0.84$. For the total $3 \mathrm{yr}$ period $\Delta T \geq 1{ }^{\circ} \mathrm{C}$ were found at wind speeds less than $1 \mathrm{~m} \mathrm{~s}^{-1}$.

During cloudy conditions, the 2 variables are not as closely related, with the correlation coefficient ranging from 0.68 in July to 0.80 in April (Fig. 6). The basic pat- 

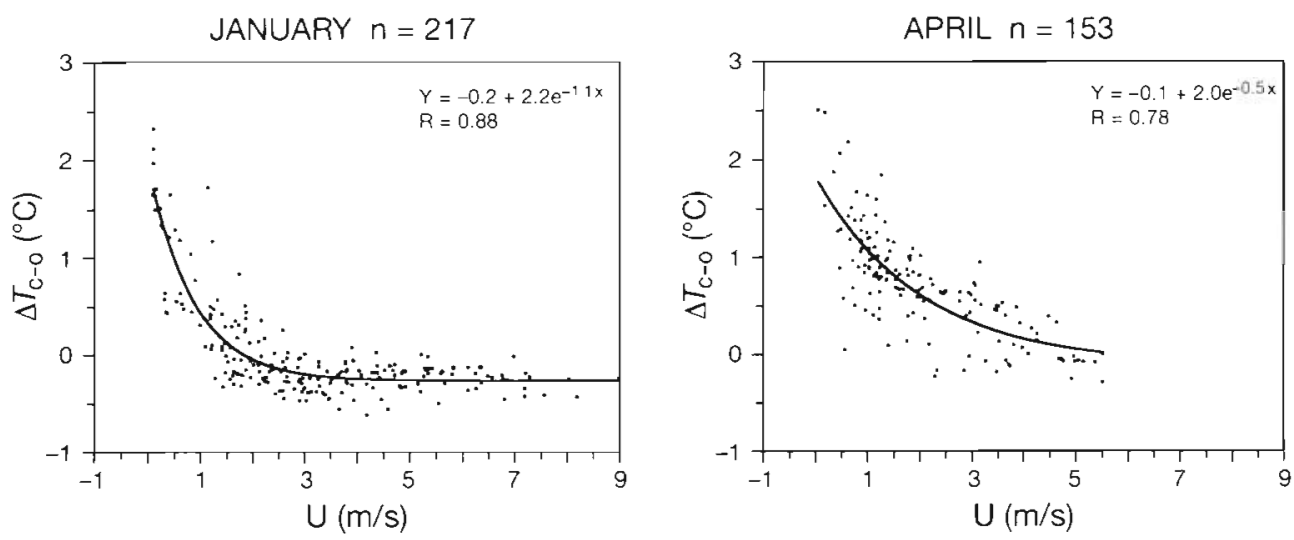

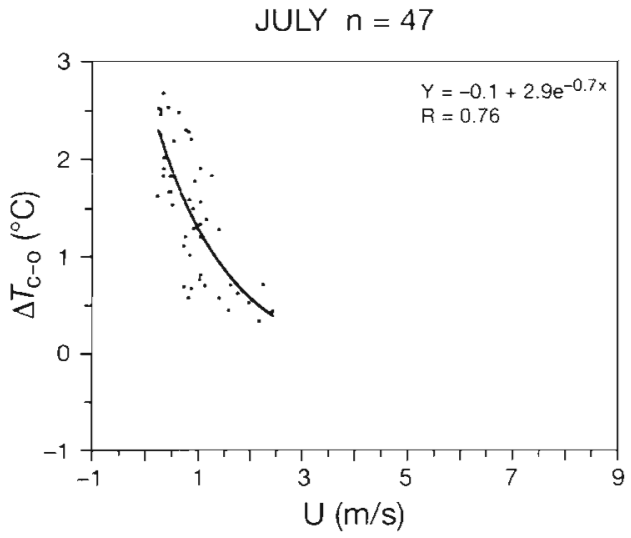

tern exhibited by the regression equations for cloudy conditions is that $\Delta T_{\mathrm{c}-0}$ is rarely greater than $1^{\circ} \mathrm{C}$, even at very low wind speeds. At higher wind speeds $\Delta T_{\mathrm{c}-0}$ approaches zero. The point scatter in Figs. 4, 5 \& 6 shows, however, that the differences seldom are lower than $-0.5^{\circ} \mathrm{C}$. These negative values are interesting, as

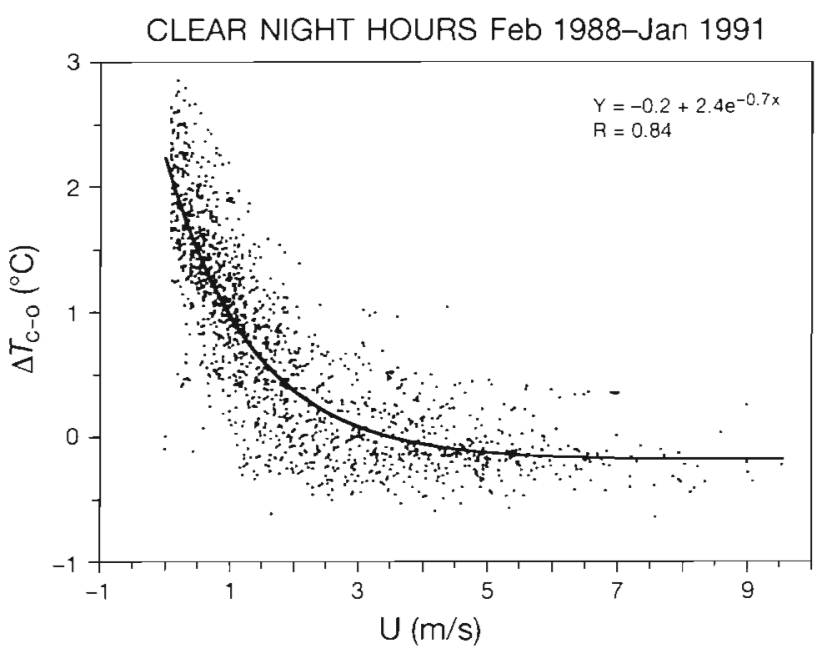

Fig. 5. $\Delta T_{c-0}$ in relation to wind speed at $10 \mathrm{~m}$ in the urban open area for the total 3 yr measuring period and clear conditions. Positive values of $\Delta T_{c-o}$ indicate higher canyon temperatures

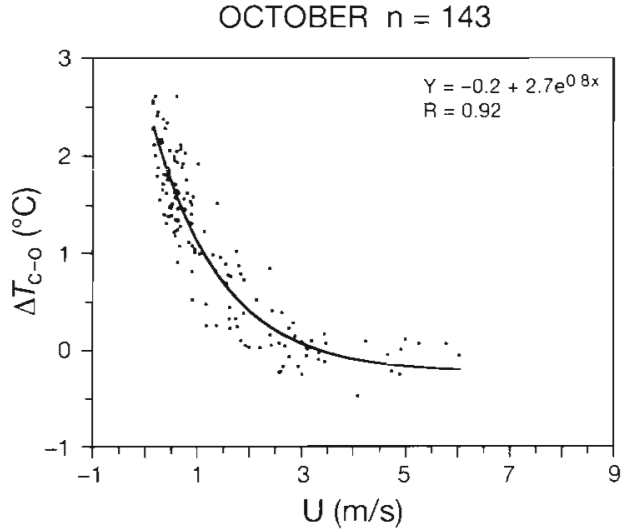

Fig. 4. $\Delta T_{c .0}$ in relation to wind speed at $10 \mathrm{~m}$ in the urban open area for every fourth month during clear conditions. Positive values of $\Delta T_{\mathrm{c}-0}$ indicate higher canyon temperatures

they indicate a lower air temperature in the canyon as compared with the open area. A possible explanation for these negative values is advection of air from the heated canyon areas into the open area (the effect is most pronounced in winter). However as these negative values lie within the resolution of the sensors, more detailed studies of the intra-urban wind and temperature field are needed.

The regression equations for the relationship between $\Delta T_{c-0}$ and the wind speed at $10 \mathrm{~m}$ in the open area during clear, semicloudy and cloudy conditions are given for July and December in Fig. 7. $\Delta T_{\mathrm{c} \text { - }}$ greater than $0.5^{\circ} \mathrm{C}$ occurred in the wind speed interval between $0 \mathrm{~m} \mathrm{~s}^{-1}$ and ca $2 \mathrm{~m} \mathrm{~s}^{-1}$ for all 3 cloudiness categories. Within this narrow wind speed interval, the highest values of $\Delta T_{c-0}$ occurred, not unexpectedly, during clear conditions. At $0.5 \mathrm{~m} \mathrm{~s}^{-1}$, however, the difference between clear and cloudy $\Delta T_{\text {c-o }}$ values was only about $1.5^{\circ} \mathrm{C}$. At wind speeds greater than $3 \mathrm{~m} \mathrm{~s}^{-1}$, the values of $\Delta T_{\mathrm{c}-\mathrm{o}}$ approached zero.

\section{MULTIPLE REGRESSION ANALYSIS}

Multiple regression equations were used for modelling urban-rural temperature differences by Sundborg (1951) and later by Lindqvist (1970). However, both 

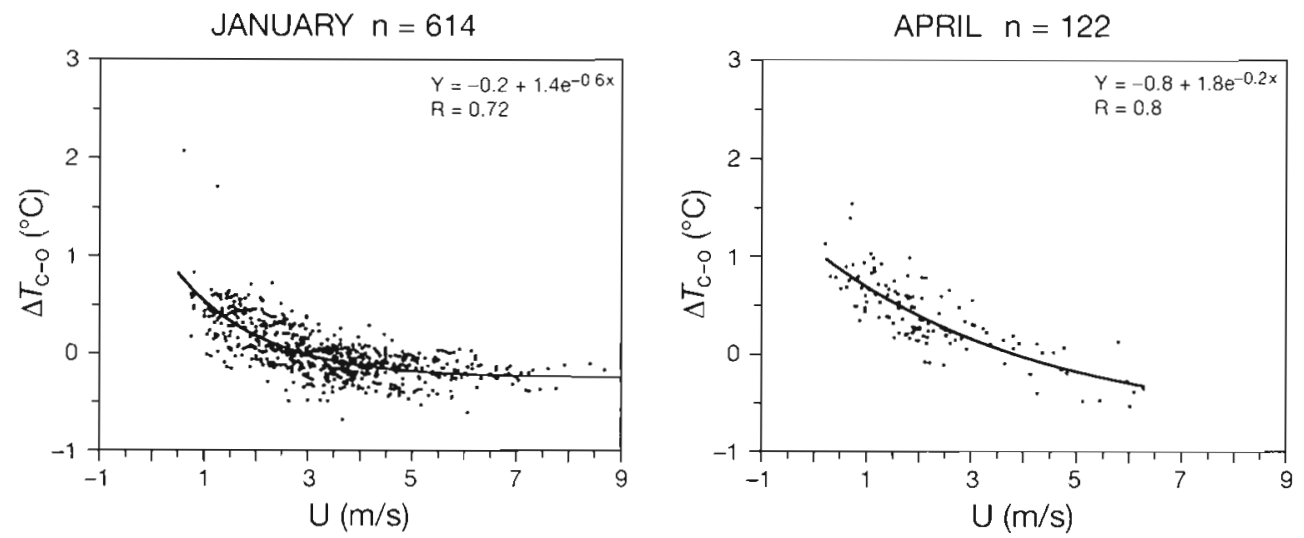

Fig. 6. $\Delta T_{\mathrm{c}-\mathrm{o}}$ in relation to wind speed at $10 \mathrm{~m}$ in the urban open area for every fourth month during cloudy conditions. Positive values of $\Delta T_{c \cdot o}$ indicate higher canyon temperatures
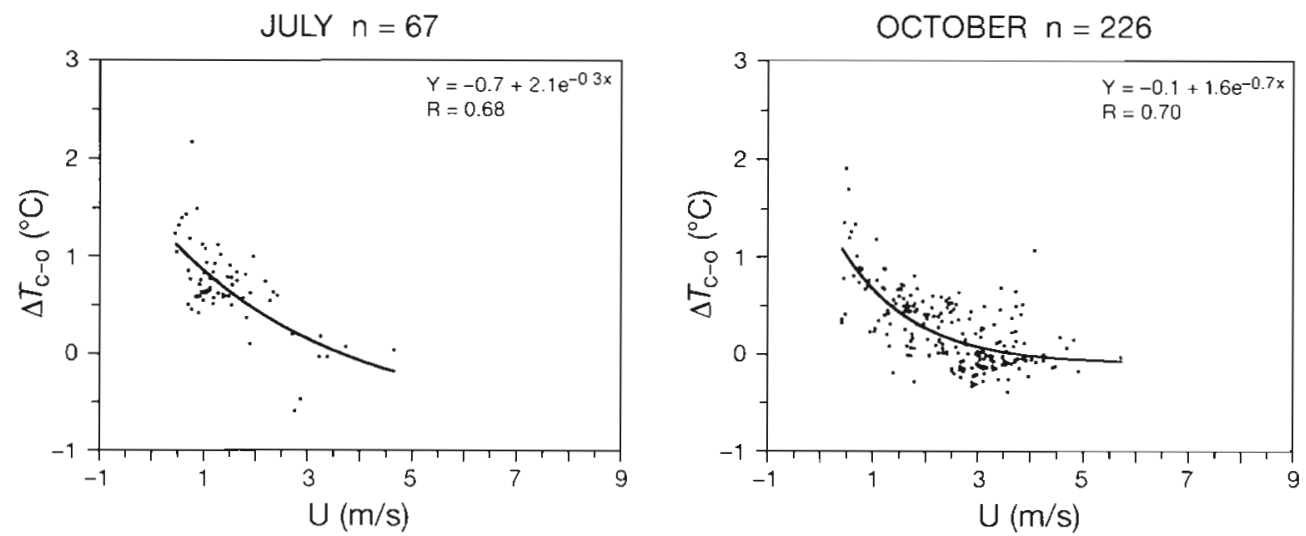

authors were doubtful as to the use of these equations. Sundborg (1951) states that 'the statistical calculations do not wholly by themselves answer questions concerning causal relations. They are to be considered only as a guidance for further investigations and theoretical studies as regards the more or less hidden physical realities'. He showed that the more simplified expression $D=(4.6-0.28 N) / U(\mathrm{R}=0.6)$, where $D=$ the urban-rural temperature difference, $N=$ cloud cover, and $U=$ wind speed, reproduced the differences better than did his multiple regression equation. Lindqvist (1970) argues that this type of equation suffers from several limitations and is thus chiefly suitable for qualitative discussions rather than quantitative analyses.

The statistical significance of a multiple regression model is generally improved by an increase in the number of parameters. The introduction of interaction factors and new variables increased the correlation
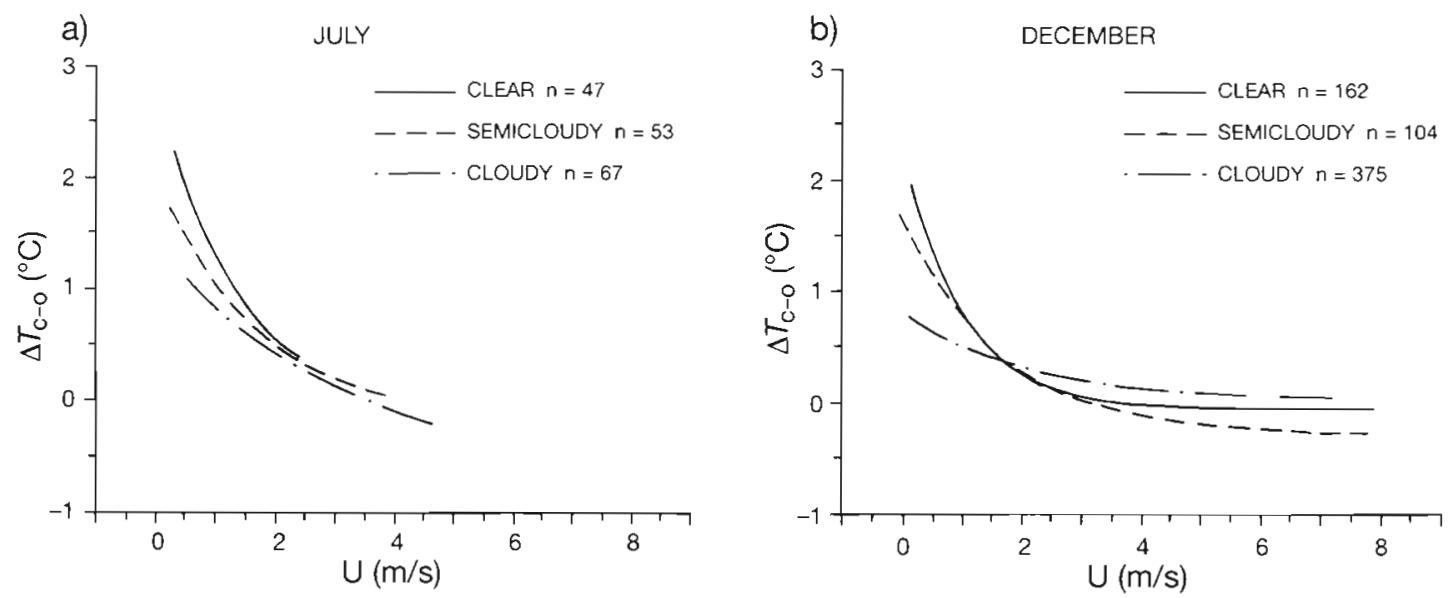

Fig. 7. $\Delta T_{c-o}$ in relation to wind speed at $10 \mathrm{~m}$ in the urban open area, under clear, semicloudy and cloudy conditions during (a) July and (b) December 
coefficients of the test models used in this study by $20 \%$ (see below). This made it interesting to try to model the intra-urban air temperature differences by multiple regression analyses.

In the present study, different models were tested on a random sample of the total 3 yr data base. The practice of SMHI of using integers for wind speeds in their statistics restricted the use of these data from the rural station, as the most interesting situations occurred at rural wind speeds lower than $3 \mathrm{~m} \mathrm{~s}^{-1}$. Thus only observations of cloud cover were used from the rural station, and the other variables, wind direction, wind speed, air temperature and air humidity, were taken from the urban open area station. Furthermore, as $\Delta T_{c-o}$ was shown to exhibit some seasonal variation (Eliasson 1996), a seasonal variable was also used. This variable was expressed as the percent of sunlit wall area in the urban canyon at 14:00 h, the time when the sun is perpendicular to the canyon (Fig. 2).

Different test models were established. As $\Delta T_{\mathrm{c}-\mathrm{o}}$ is known to be non-linearly related to wind speed, a model using the urban open area wind speed at $10 \mathrm{~m}$ as the denominator was tested. However, it was necessary to reject the model showing the best coefficient of determination, as a chi-squared goodness-of-fit test showed non-normally distributed residuals.

It was concluded that linear multiple regression models with the variables total amount cloud cover at the rural station $\left(N_{\mathrm{r}}\right)$, urban open area wind speed $\left(U_{\mathrm{u}}\right)$ and percentage of sunlit canyon wall $\left(S_{\mathrm{c}}\right)$ gave the highest level of statistical significance. The variables wind direction, distance from the surface to the lowest cloud base, air temperature and air humidity were found to be statistically insignificant at the $1 \%$ level in the regression analysis.

Finally, 2 different models were tested on the total 3 yr data base (nighttime hours). The first model is simply a fit of $\Delta T_{r-0}$ by means of the amount of cloud cover at the rural station $\left(N_{\mathrm{r}}\right)$ and the wind speed at the urban open area $\left(U_{\mathrm{u}}\right)$, giving the model:

$$
\Delta T_{\mathrm{c}-0}=\beta_{0}+\beta_{1} U_{\mathrm{u}}+\beta_{2} N_{\mathrm{r}}+\beta_{3} U_{\mathrm{u}} N_{\mathrm{r}}+e
$$

where each $\beta_{1}$ term $(i=1,2, \ldots)$ stands for the regression parameters immediately following it and $e$ is the residual. In the second model, the seasonal variable $\left(S_{c}\right)$ has been added, giving the model:

$$
\begin{aligned}
& \Delta T_{\mathrm{c}-\mathrm{o}}= \\
& \quad \beta_{0}+\beta_{1} S_{\mathrm{c}}+\beta_{2} U_{\mathrm{u}}+\beta_{3} N_{\mathrm{r}}+\beta_{4} U_{\mathrm{u}} N_{\mathrm{r}}+\beta_{5} U_{\mathrm{u}} S_{\mathrm{C}}+\beta_{6} S_{\mathrm{c}} N_{\mathrm{r}}+e
\end{aligned}
$$

where each $\beta_{i}$ term $(i=1,2, \ldots)$ stands for the regression parameters immediately following it and $e$ is the residual.

The models include interaction factors, i.e. the product $U_{\mathrm{u}} N_{\mathrm{r}}$ (models 1 and 2), $U_{\mathrm{u}} S_{\mathrm{c}}$ (model 2) and $S_{\mathrm{c}} N_{\mathrm{r}}$ (model 2). It was shown statistically by the present analysis that models that included interaction factors increased the coefficients of determination by $20 \%$ units as compared to models which did not include interaction factors.

Owing to the high latitude of Göteborg $\left(57^{\circ} 42^{\prime} N\right)$, the length of the night varies greatly during the year. In the middle of June, the nights are approximately $6 \mathrm{~h}$ long and, in December, about $16 \mathrm{~h}$ long. Thus if the total length of the night is to be considered in the analysis, this means that there is approximately 3 times as much data available for the winter as for summer months. Moreover, previous studies have shown that during winter $\Delta T_{c-0}$ increases from sunset to a maximum value a few hours after sunset, thereafter remaining stable (Eliasson 1994, Fig. 5). In order to test if the difference between winter and summer data would affect the analysis, 2 models were tested on 2 data sets. Data set $A$ consisted of the total length of the night and data set $B$ of the 5 night hours beginning after sunset. This means that the entire night during summer is considered in data set $\mathrm{B}$, while only the first $6 \mathrm{~h}$ of the night are considered for winter.

The regression parameters and correlation coefficients from the multiple regression analysis of models 1 and 2 using data sets $A$ and $B$ are given in Table 1. All variables in both models were significant at the $1 \%$ level and a chi-squared goodness-of-fit test showed that the residuals were normally distributed. The correlation coefficients were low, ranging from 0.6 to 0.7 . The results showed that both models gave similar regression equations for data sets $\mathrm{A}$ and $\mathrm{B}$ under clear conditions. On occasions of high cloud cover the equations showed a small variation between data sets A and $B$ (model 2) but, as cloudy conditions are of minor

Table 1. Results from the multiple regression analysis of models 1 and 2 using data sets $A$ and $B$. Regression coefficients $\left(\beta_{1}\right)$ and correlation coefficients (R) are shown. Explanation of models (1. and 2) and data sets (A and B) are given in the text

\begin{tabular}{|lcccccccc}
\hline Data/Model & \multicolumn{7}{c}{ Regression coefficient: } \\
& $\beta_{0}$ & $S_{\mathrm{c}}$ & $U_{\mathrm{u}}$ & $N_{\mathrm{r}}$ & $U_{\mathrm{u}} N_{\mathrm{r}}$ & $U_{\mathrm{u}} S_{\mathrm{c}}$ & $S_{\mathrm{c}} N_{\mathrm{r}}$ \\
\hline $\mathrm{A} / 1$ & 1.4301 & - & -0.3290 & -0.1219 & 0.0262 & - & - & $-\mathrm{R}$ \\
$\mathrm{B} / 1$ & 1.4541 & - & -0.3374 & -0.1147 & 0.0247 & - & - & 0.60 \\
$\mathrm{~A} / 2$ & 0.9399 & 0.0134 & -0.2067 & -0.0900 & 0.0216 & -0.00381 & -0.000530 & 0.70 \\
$\mathrm{~B} / 2$ & 0.7411 & 0.0512 & -0.1692 & -0.0588 & 0.0161 & -0.00389 & -0.000787 \\
\hline
\end{tabular}


importance for the prediction of $\Delta T_{c-0}$, this difference was not analysed further.

The regression parameters for data sets $A$ and $B$ are so similar that the effect of the later part of the winter nights, when $\Delta T_{c-o}$ has reached a stable value, on the model must be regarded as insignificant. Thus only data set $\mathrm{A}$ (the total data) is used in the subsequent discussion. The coefficients (Table 1) show that increases in both cloud cover and wind speed decrease the value of $\Delta T_{c-0}$. However, the seasonal variable $\left(S_{c}\right)$ shows a positive $\beta$ coefficient, which means that the summer (high $\left.S_{c}\right)$ would exhibit a larger $\Delta T_{c-o}$ than the winter. The role of the interaction factors is to compensate for the interplay between the variables in the equation. For example, an increased wind speed is often associated with an increased amount of cloud cover, which results in an overestimation of the effect. In the present equations (Table 1) this means that large negative values are compensated for by a positive interaction factor, $U_{\mathrm{u}} N_{\mathrm{r}}$. On the other hand, an increased value of the variable $S_{c}$ (positive coefficient) is linked to a decreased amount of cloud cover (negative coefficient). This results in an underestimation of the effect, which is then compensated for by a negative interaction factor, $S_{\mathrm{c}} N_{\mathrm{r}}$
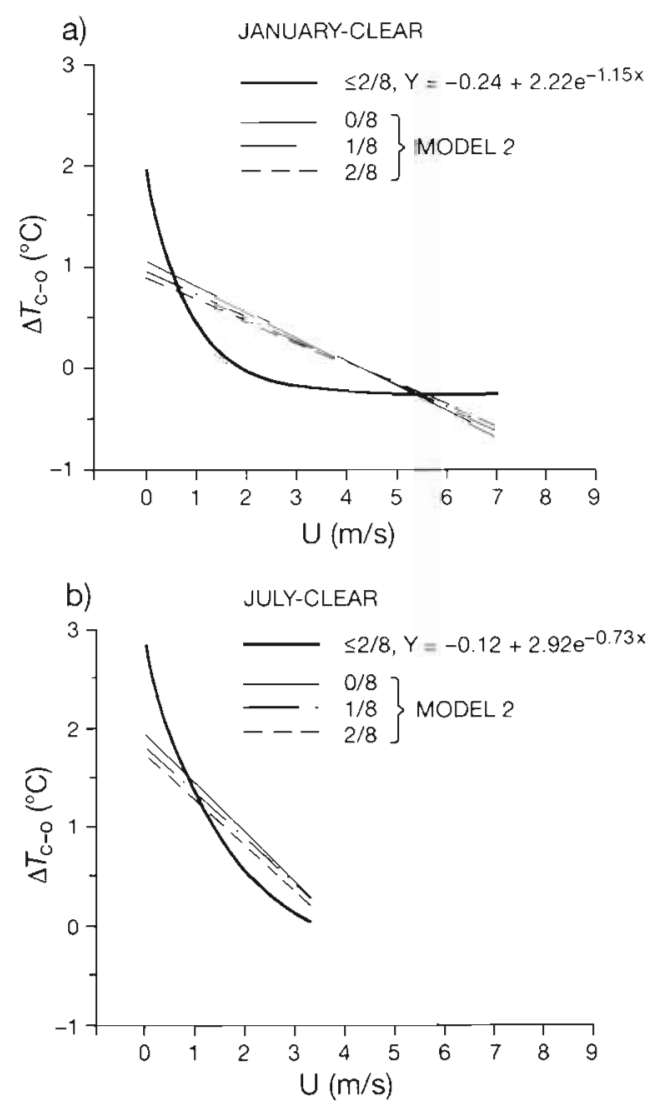

Fig. 8. Comparisons of the linear multiple regression equations determined using model 2 for data set $A$ with the nonlinear equations of the relationship with wind speed. Clear conditions; (a) January, (b) July

\section{COMPARISION OF THE TWO METHODS FOR PREDICTION OF INTRA-URBAN TEMPERATURE DIFFERENCES}

Wind speed and amount of cloud cover were found to be the most important factors for predicting the intra-urban air temperature differences found by point measurements in a canyon $(S V F=0.5)$ and an open area $(S V F=1.0)$. The differences were confined to a very narrow wind speed interval. If only $\Delta T_{c-0}$ values greater than $0.5^{\circ} \mathrm{C}$ are considered to be of interest, these values are found in the interval of 0 to $2 \mathrm{~m} \mathrm{~s}^{-1}$, especially during clear conditions. To assess the reasonableness of the multiple regression analysis, these results are compared with the multiple regression equations determined using model 2 and data set $\mathrm{A}$. (Figs. $8 \& 9$ ). From these diagrams, which show the results for January and July during clear and cloudy conditions, it is evident that the multiple regression equations are insufficient for modelling $\Delta T_{c-0}$. Under both clear and cloudy conditions in all seasons, the multiple regression equations fail to estimate the highest $\Delta T_{\mathrm{c}-\mathrm{o}}$ found at low wind speeds. During clear weather, the equations overestimate $\Delta T_{\mathrm{c}-\mathrm{o}}$ values for
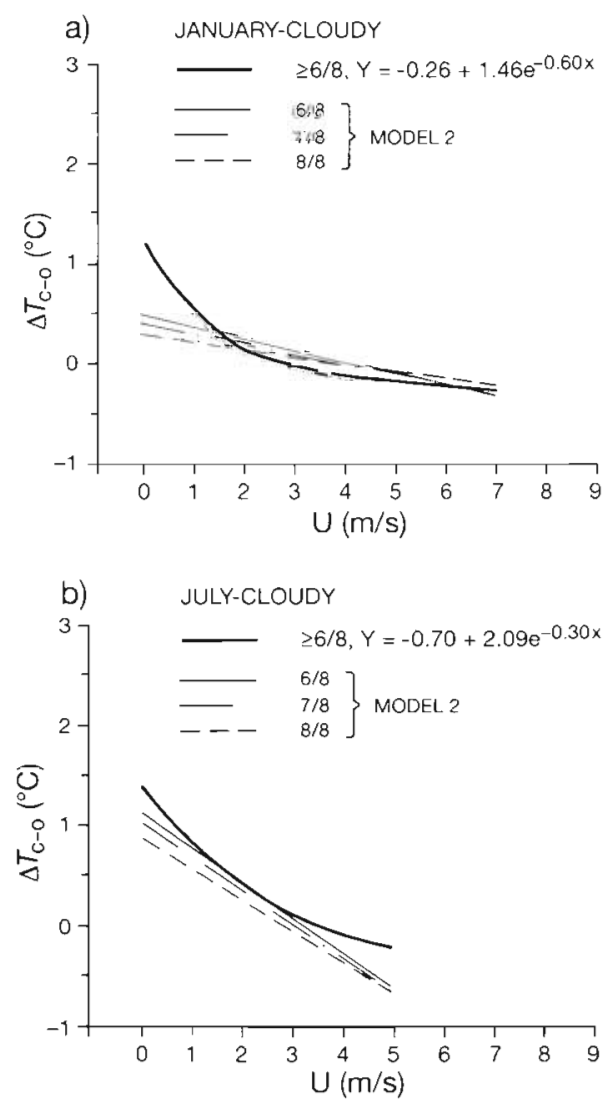

Fig. 9. Comparisons of the linear multiple regression equations determined using model 2 for data set $A$ with the nonlinear equations of the relationship with wind speed. Cloudy conditions; (a) January, (b) July 
wind speeds greater than $1 \mathrm{~m} \mathrm{~s}^{-1}$. The best correspondence between the 2 methods is for cloudy conditions at wind speeds higher than $1 \mathrm{~m} \mathrm{~s}^{-1}$. Thus the equations are not sufficiently accurate for modelling $\Delta T_{c-o}$ greater than $0.5^{\circ} \mathrm{C}$. This effect is, of course, the result of these linear equations being based on the total data, which includes all weather types and in which clear and calm nighttime hours are in the minority.

In conclusion, the results show that the intra-urban air temperature differences recorded in Göteborg can be described with a reasonably high level of accuracy by using wind speed data from the urban open area and the amount of cloud cover from a standard meteorological station. The proposed model, a non-linear regression equation, is of importance for architects and planners as it describes how different urban geometries affect the local climate in a city. The model is most suitable for the detailed planning level but could also be helpful for land use planning on a more general survey level, for example the whole city. As a complement to local climatological maps the proposed model could give important indications, from the point of view of comfort, energy economy and the effect of climate, for use in locating and adjusting built-up areas. As the regression coefficients are only valid for the measurement sites presented in this paper, the proposed model could only be used directly for local planning in the city of Göteborg. However, the methodology and the general pattern of the model should also be valid for other cities, and the results can serve as a guide for the degree of intra-urban temperature variations found in the centre of a city with a classical European urban structure. Field measurements made over short durations may make the equation applicable for sites not specified in this paper. The results, for example the narrow interval in which the wind speed is sensitive to changes in $\Delta T$, may have implications for the development of models valid for other regions and for the choice of instruments.

Acknowledgements. Financial support was received from the Swedish Council for Building Research. Prof. Sven Lindqvist, advisor for the project, Dr Björn Holmer and Dr Deliang Chen offered valuable comments on the manuscript. Thanks also go to Dr Johan Jonasson, Department of Mathematics, Göteborg University, who assisted with the statistical analyses.

\section{LITERATURE CITED}

Arnfield AJ (1982) An approach to the estimation of the surface radiative properties and radiation budgets of cities. Phys Geogr 3:97-122

Arnfield AJ (1990) Canyon geometry, the urban fabric and nocturnal cooling: a simulation approach. Phys Geogr 11 : 220-239

Bärring L, Mattsson JO, Lindqvist S (1985) Canyon geometry, street temperatures and urban heat island in Malmö. Sweden. J Clim 5:433-444

Carlson TN, Dodd JK, Benjamin SG, Cooper JN (1981) Satellite estimation of the surface energy balance, moisture availability and thermal inertia. J Appl Meteorol 20:67-87

Eichhorn J, Schrodin R, Zdunkowski W (1988) Threedimensional numerical simulations of the urban climate. Beitr Phys Atmos 61(3):187-203

Eliasson I (1990/91) Urban geometry, surface temperature and air temperature. Energy Buildings 15-16:141-145

Eliasson I (1992) Infrared thermography and urban temperature patterns. Int J Remote Sens 13(5):869-879

Eliasson I (1994) Urban-suburban-rural air temperature differences related to street geometry. Phys Geogr 15(1):1-22

Eliasson I (1996) Urban nocturnal temperatures, street geometry and land use. Atmos Environ Part B Urban Atmos 30(3):379-392

Eliasson I, Holmer B (1990) Urban heat island circulation in Göteborg, Sweden. Theor Appl Climatol 42:187-196

Evans JM, Schiller S (1991) Climate and urban planning: the example of the planning code for Vicente Lopez, Buenos Aires. Energy Buildings 15:35-41

Johnson CT, Okc TR, Lyons TJ, Steyn DG, Watson ID, Voogt JA (1991) Simulation of surface urban heat islands under 'ideal' conditions at night, Part 1, Theory and tests against field data. Boundary-Layer Meteor ol 56:275-294

Kuttler W (1993) Planungsorientierte Stadtklimatologie, Aufgaben, Methoden und Fallbeispiele. Geogr Rundschau 45(2):95-106

Lindqvist S (1970) Bebyggelseklimatologiska Studier. Meddelande från Lunds Universitets Geografiska Institution, Avhandlingar LXI, Gleerup, Lund (with summary in English)

Lindquist $S$ (1991) Local climatological maps for planning. University of Göteborg, Department of Physical Geography, GUNI report 32

Lindqvist S, Mattsson JO (1989) Planning -topography and climate; topoclimatic maps for different planning levels: some Swedish examples. Building Research and Practice, The Journal of CIB 5:300-304

Myrup L (1969) A numerical model of the urban heat island J Appl Meteorol 8:908-918

Oke TR (1981) Canyon geometry and the nocturnal urban heat island: comparision of scale model and field observations. J Climatol 1:237-254

Oke TR (1988) Street design and urban canopy layer climate Energy Buildings 11:103-113

Park HS (1987) City size and urban heat island intensity for Japanese and Korean cities. Geogr Rev Jap 60:238-250

Sundborg $\AA$ (1951) Climatological studies in Uppsala. Geographica No. 22. Uppsala University, Dept of Geography

Terjung WH, O'Rourke PA (1980a) Influences of physical structures on urban energy budgets. Boundary-Layer Meteorol 19:421-439

Terjung WH, O'Rourke PA (1980b) Simulating the causal elements of urban heat islands. Boundary-Layer Meteorol 19: $93-1.1 .8$

Todhunter PE (1990) Microclimatic variations attributable to urban-canyon asymmetry and orientation. Phys Geogr 11 $131-1.41$

Voogt JA, Oke TR (1991) Validation of an urban canyon radiation model for nocturnail long-wave fluxes. BoundaryLayer Meteorol 54:347-361

Yoshida A (1992) Numencal analysis of heat transfer in urban canyon. Paper presented at the 2nd Tohwa International Symposium, CUTEST'92, 7-10 September, Fukuoka, Japan. Tohwa University, Fukuoka 